\title{
Performance Research of Private Investment-Case Study of Nanjing
}

\author{
Jianfei Leng1,2, Qun Zhang2, Pei Tang² \\ ${ }^{1}$ School of Management, Fudan University, Shanghai, China \\ ${ }^{2}$ Business School, Hohai University, Jiangsu, China \\ Email: ljf200209@163.com, 1245206010@qq.com
}

Received 20 August 2014; revised 18 September 2014; accepted 12 October 2014

Copyright (C) 2014 by authors and Scientific Research Publishing Inc.

This work is licensed under the Creative Commons Attribution International License (CC BY).

http://creativecommons.org/licenses/by/4.0/

c) (i) Open Access

\begin{abstract}
This paper analyzes the function of the transportation, energy supply, water supply, telecommunications, environmental protection and other infrastructure factors on private investment, and takes the city of Nanjing as an example for the empirical analysis. Based on data from 1992 to 2011 for factor analysis, we conclude that infrastructure has promoted to private investment and that the level of infrastructure has become the bottleneck of economic development. For this reason, we should continue to improve its quantity and quality.
\end{abstract}

\section{Keywords}

\section{Infrastructure, Private Investment, Principal Component Analysis, Performance Study}

\section{Introduction}

Infrastructure investment, are those basic services investments which engaged in the production, life, development and other recreational activities needed, through powers of intervention by the State or public resources to provide, such as roads, railways, ports, bridges, airports, hydro and gas, telecommunications and meteorological services and so on. But establishing a sound infrastructure often takes a long time and huge investment, and it often plays an indispensable role in the development of a society. With the basic features and external characteristics, basic infrastructure provides necessary protection for normal production of private companies, and reduces the private sector's information and transportation costs.

Since the reform and opening up, infrastructure of Nanjing has been greatly improved, as the investment in infrastructure increases each year to optimize the investment environment. However, due to limited government funding and the infrastructure construction involving numerous projects, covering a wider area needs huge funds and long construction period. Also, investment decisions have certain subjectivity thus that caused some prob- 
lems for infrastructure construction. It mainly reflected in three aspects: unreasonable investment in infrastructure industries, duality of urban and rural infrastructure investment, and duality within the city.

The money of government investments in public goods is limited. More investment in infrastructure inevitably means less investment in other aspects. For example, government's investment in transport, energy, communications, and other aspects are excessive, especially when government perform extensible economic policy, a lot of money is invested in railways, roads, and less in health, education, science and technology, environmental protection, causing the industrial structure infrastructure extremely unreasonable.

\section{Contains Elements of Infrastructure}

Based on the results of Liu Junsheng [1], Yin Wenjing [2], Shi Shengqiang [3] and Chen Zhenling [4] and other scholars, the paper boils down the elements of infrastructure to the following five categories.

\subsection{Transportation Factors}

Transportation is an important basic industry of the national economy, the infrastructure of social economy and an important link, playing an important role in resource allocation and macro-control. Construction of convenient transport system contributed to the formation of regional industry gathering and economies of scale, economies of scale will lead to reduce of the average cost of companies. However, the development of specialization and the formation of economies of scale depend on the elements created by infrastructure. They also depend on transfer of products space, and on facilitate of the production and transaction as well. So it plays an important role in promotion of social division, the formation of large-scale industrial development and in economies of scale.

Nanjing located in Yangtze River Delta region, and also in the Beijing-Shanghai line, is an important central city of the Yangtze River basin, therefore, its transportation is extremely important. Since the reform and opening up, Nanjing has become integrated transport hub contain the road, rail, sea, air, and pipeline.

\subsection{Energy Supply Factors}

Energy is necessary inputs in production and reproduction, such as the supply of coal, oil, natural gas, electricity. And it is indispensable in production. In recent years among the regions plagued by the shortage of electricity, private enterprises suffered great impact .Without enough power, companies cannot work normally or there is "starting day of rest days" phenomenon. Meanwhile, energy prices constitute the cost of enterprise products and services. Changes in energy prices and the performance would inevitably lead to a chain reaction of private enterprises. With the constant increase in oil prices in the domestic, private enterprise production costs will fluctuate; the incentives of private investment took a hit.

Abundant supply of coal, gasoline, fuel, electricity and other energy sources provide adequate protection for the development of private enterprises. In the last 20 years, the consumption of gasoline, diesel, fuel oil of industrial enterprises in Nanjing has declined, from 101,381 tons, 256,142 tons, 1,493,609 tons in 1992 dropped to 33,723 tons, 105,156 tons, 191,908 tons in 2011. Instead, the consumption of coal, electricity, from 7,220,876 tons, 4,378,320,000 $\mathrm{kWh}$ in 1992 increase to 27,770,418 tons, 24,261,130,000 kWh in 2011, and the annual growth rate reached 14.23 percent, 22.71 percent. Government invests greatly in construction of the energy supply. Energy supply infrastructure has also been improved. These also provide a guarantee smooth for production of enterprises.

\subsection{Water Supply and Drainage Factors}

Water supply and drainage involve many aspects such as water supply, drainage, purification, flood control, water pollution control, water conservation and utilization and so on. And it is closely related with industrial production, people's lives, urban construction and environmental protection. Water is extremely important for most businesses now. Without water supply, business is difficult to product normally. Emissions of industrial wastewater, sewage and rainwater are equally important. If waste water can't be disposed and utilized well, it will affect the safety of water quality and efficient use of water resources.

Nanjing made great progress in the comprehensive production capacity for water, water supply, water saving, production of repeated water. An average annual growth rate gets to $9.2 \%, 6.2 \%, 8.9 \%$ and $5.5 \%$, which effectively meets the private enterprises’ production in Nanjing, and also improve the efficiency of production. 


\subsection{Postal and Telecommunications Factors}

Posts and telecommunications utilities play an important role in the national economy. It is not only important industry of national economy, but also the basis of other departments' development. Developed construction of postal communications equipment, can greatly facilitate the modern information and secure communication. Enterprises are more convenient to gather market information and insight into market trends via telephone, Internet, and timely change the production plans, reduce the company's market risk. At the same time, developed communications equipment make communication between businesses more convenient to exchange information, thus this greatly reduces transaction costs of enterprises.

Into the nineties, Posts and Telecommunications in Nanjing has been developed rapidly, infrastructure of post and telecommunications has also been improved. In 2011, total business of Posts and Telecommunications, the telephone penetration rate, the total length of the Post were 16.61 times, 34.49 times and 2.20 times in 1992.

\subsection{The Factors of Environmental Protection}

A good ecological environment has become an important factor in the city's comprehensive competitiveness that can enhance the city's attractiveness and cohesiveness, and that can attract a large number of enterprises to invest in production in the city. On the one hand, good ecological environment creates a suitable living and production environment for private enterprises. Such as in the Nanjing Jiangning Technology Development Zone, Suzhou Singapore Industrial Park, beautiful environment and fresh air make people work in a comfortable environment, and attract more enterprises and talents to enter. On the other hand, companies can reduce its own energy consumption and reduce production costs, save money by additional investment for businesses in the utilization of "waste" products, water conservation, and development of circular economy. Enterprises get development mode of lower pollution, low emission, low energy consumption, high efficiency through technological innovation, system innovation, industrial restructuring, new energy development and other means to reduce especially the consumptions of coal, oil and other carbon energy. This kind of development mode of low carbon economy can keep private enterprises survive all the time in the pattern of sustainable development, and provide the guarantee mechanism for the long-term survival of enterprises.

\section{Empirical Analysis}

\subsection{Selected Variables}

According to Zheng Qunfeng [5], Liao Jiaxin [6] and Zhang Wenjuan [7] and other scholars' researches, the paper selected the following 15 areas as the study variables, and found the data from 1992 to 2011, a total of 20 years of data. All data are from Nanjing Statistical Yearbook.

15 variables were: public transportation vehicles per 10,000 population, road area per capita, volume of passenger traffic, the total volume of cargo transport, total consumption of coal, power consumption, comprehensive production capacity of water, water conservation, sewage treatment capacity per day, compliance rate of wastewater discharge, telephone penetration rate (including mobiles and fixed phones), postal total length, urban (built-up area) green coverage rate, comprehensive utilization rate of industrial solid waste, comprehensive utilization of industrial solid wastes.

\subsection{Applicability Test of Variable}

KMO test showed, KMO statistic is 0.812 , higher than 0.5 , indicating suitable for factor analysis (Table 1 ).

From Table 2, we can see there is a significant eigenvalues in variables correlation matrix: 12.684, the cumulative contribution rate has reached $84.559 \%$, indicating that a main factor can be expressed enough information of the original data. In the analysis, set the standards of extraction principal component is eigenvalues greater than 1. Extract two main components to describe the original overall index; the cumulative variance of a principal component was $84.559 \%$, basically reflecting 15 information indicators.

Using method of principal component analysis, select a factor F1 (=12.684) according to standard of eigenvalues greater than 1 , the cumulative variance contribution rate of $84.559 \%$, the ability to explain, it can be considered a reasonable common factors representation of linear relationship of each factor, basically able to explain most of the information of the original data, the extracted common factors have better representation. 
Table 1. The test of KMO and Bartlett.

\begin{tabular}{lcc}
\hline \multicolumn{2}{c}{ Kaiser-Meyer-Olkin Measure of Sampling Adequacy } & 0.812 \\
& Approximate chi-square & 586.327 \\
Bartlett's test of sphericity & Df & 105 \\
& Sig. & 0.000 \\
\hline
\end{tabular}

Table 2. Characteristic value and the contribution rate.

\begin{tabular}{|c|c|c|c|c|c|c|}
\hline \multirow{2}{*}{ Ingredients } & \multicolumn{3}{|c|}{ The initial eigenvalues } & \multicolumn{3}{|c|}{ Extracting square and load } \\
\hline & Total & Variance \% & Accumulation \% & Total & Variance \% & Accumulation \% \\
\hline 1 & 12.684 & 84.559 & 84.559 & 12.684 & 84.559 & 84.559 \\
\hline 2 & 0.834 & 5.558 & 90.118 & & & \\
\hline 3 & 0.446 & 2.974 & 93.091 & & & \\
\hline 4 & 0.388 & 2.586 & 95.677 & & & \\
\hline 5 & 0.279 & 1.860 & 97.537 & & & \\
\hline 6 & 0.119 & 0.792 & 98.329 & & & \\
\hline 7 & 0.106 & 0.709 & 99.038 & & & \\
\hline 8 & 0.055 & 0.368 & 99.406 & & & \\
\hline 9 & 0.047 & 0.311 & 99.718 & & & \\
\hline 10 & 0.016 & 0.105 & 99.823 & & & \\
\hline 11 & 0.013 & 0.084 & 99.907 & & & \\
\hline 12 & 0.008 & 0.053 & 99.960 & & & \\
\hline 13 & 0.004 & 0.029 & 99.989 & & & \\
\hline 14 & 0.001 & 0.009 & 99.998 & & & \\
\hline 15 & 0.000 & 0.002 & 100.000 & & & \\
\hline
\end{tabular}

As can be seen from Table 3, the common factor (F1) has a relatively large load on indicators of road area per capita (square meters), power consumption (10,000 kwh), telephone penetration rate (including mobile and fixed phones), sewage treatment capacity $(10,000 \mathrm{t})$, and comprehensive utilization of solid industrial waste (10,000 t), which is more than five indicators reflect the state of the infrastructure point of view, this factor is named public infrastructure factors. The five indicators multi-side reflects the condition of infrastructure, and will this common factor named infrastructure factor.

\subsection{Calculation of Orthogonal Factors to Obtain Function Formula}

According to Table 4, we get the following function formula:

$\mathrm{F}_{1}=0.064 \times$ public transportation vehicles per 10,000 population (standard units) $+0.076 \times$ road area per capita (square meters) $+0.075 \times$ volume of passenger traffic $(10,000$ person $)+0.070 \times$ the total volume of cargo transport $(10,000 \mathrm{t})+0.069 \times$ the consumption of raw coal $(\mathrm{t})+0.078 \times$ consumption of electric power $(10,000$ $\mathrm{km} / \mathrm{h})+0.071 \times$ comprehensive production capacity of water $(10,000$ cubic meters/day $)+0.073 \times$ save water $(10,000$ cubic meters $)+0.077 \times$ sewage treatment capacity per day $(10,000 \mathrm{t})+0.072 \times$ compliance rate of wastewater discharge $(\%)+0.077 \times$ phone penetration rate (including mobile and fixed phones) $+0.072 \times$ postal total length $(\mathrm{km})+0.072 \times$ urban (built-up area) green coverage rate $(\%)+0.061 \times$ comprehensive utilization rate of industrial solid waste $(\%)+0.078 \times$ comprehensive utilization of industrial solid waste $(\mathrm{t})$.

\subsection{Calculate the Factor Scores and Sort of Comprehensive Performance Scores}

Through factor analysis can get the score of each factor, and then use the variance contribution rate as weights, constructs the index $\mathrm{Z}$ of performance of private investment.

Comprehensive Performance $\mathrm{F}=$ (Variance contribution rate of F) F1

$$
\mathrm{F}=\mathrm{F} 1
$$

According to the actual meaning of factor, infrastructure factor F1 reflects $100 \%$ of the private investment performance. 
Table 3. Component matrix.

\begin{tabular}{cc}
\hline & Component \\
Electric power (10,000 kwh) & 1 \\
\cline { 2 - 2 } Comprehensive utilization of industrial solid waste (10,000 t) & 0.991 \\
Telephone penetration rate (including mobile and fixed phones) & 0.984 \\
Sewage treatment capacity per day (10,000 t) & 0.983 \\
Road area per capita (square meters) & 0.977 \\
Volume of passenger traffic (10,000 person) & 0.962 \\
Water conservation (10,000 cubic meters) & 0.946 \\
Compliance rate of wastewater discharge (\%) & 0.921 \\
Postal total length (km) & 0.919 \\
Urban green coverage rate (\%) & 0.915 \\
Comprehensive production capacity (10,000 cubic meters·day ${ }^{-1}$ ) & 0.915 \\
The total volume of cargo transport (10,000 t) & 0.897 \\
The raw coal (t) & 0.887 \\
Public transportation vehicles per 10,000 population (standard units) & 0.878 \\
Comprehensive utilization rate of industrial solid wastes (\%) & 0.812 \\
\hline
\end{tabular}

Table 4. Component score coefficient matrix.

\begin{tabular}{cc}
\hline & Component \\
\cline { 2 - 2 } Public transportation vehicles per 10,000 population (standard units) & 1 \\
Road area per capita (square meters) & 0.064 \\
Volume of passenger traffic (10,000 person) & 0.076 \\
The total volume of cargo transport (10,000 t) & 0.075 \\
The raw coal (t) & 0.070 \\
Electric power (10,000 km/h) & 0.069 \\
Comprehensive production capacity (10,000 cubic meters/day) & 0.078 \\
Water conservation (10,000 cubic meters) & 0.071 \\
Sewage treatment capacity per day & 0.073 \\
Compliance rate of wastewater discharge (\%) & 0.077 \\
Telephone penetration rate (including mobile and Nong Hua) & 0.072 \\
Postal total length (km) & 0.077 \\
Urban green coverage rate (\%) & 0.072 \\
Comprehensive utilization rate of industrial solid wastes (\%) & 0.072 \\
Comprehensive utilization of industrial solid waste (10,000 t) & 0.061 \\
\hline
\end{tabular}

Table 5 shows that the scores of main component reached the highest value 1308840.443 in 2008. Because of the development of transport, the improvement of energy supply, the development of communications and environmental protection, private investment in Nanjing increases rapidly. But during 2010 and 2011, for the spread of the international financial crisis, private investment has also been affected, thus there is a slight decrease in the value of $\mathrm{F}$, respectively 1239586.33 and 1244582.317.

Table 5 also shows that the highest value of overall performance in 2008 (1308840.4), is almost equivalent to 2009 values (1296528.7), and the lowest value is in 1992 (468795.87). From 1992 to 2007, the overall performance value is increasing year by year, and the amount of investment in infrastructure also increase every year, including great improvement in aspects of transportation, energy supply, water supply, telecommunications and environmental protection. Contribution rate of factors of infrastructure on private investment is 84.559 percent, in the early stages of development of private investment, the level of urban facilities, supply of coal, electric and water, telecommunications and landscaping are backward, thus lack of investment capital. So after getting better infrastructure improvements, the impact on private investment is obvious. In the two years 2010 and 2011, due to the impact of the financial crisis, investment in state-owned enterprises have also been impacted. Though the 
Table 5. The score of factor and comprehensive ranking.

\begin{tabular}{cccc}
\hline Year & Infrastructure factor score F1 & Comprehensive performance F & Ranking \\
\hline 2008 & 1308840.443 & 1308840.4 & 1 \\
2009 & 1296528.671 & 1296528.7 & 2 \\
2011 & 1244582.317 & 1244582.3 & 3 \\
2010 & 1239586.33 & 1239586.3 & 4 \\
2007 & 1206918.225 & 1206918.2 & 6 \\
2006 & 1095526.624 & 1095526.6 & 7 \\
2005 & 970950.7395 & 970950.74 & 8 \\
2004 & 902810.0832 & 902810.08 & 9 \\
2003 & 798964.8849 & 798964.88 & 10 \\
2002 & 768262.1901 & 768262.19 & 11 \\
1997 & 710819.2785 & 710819.28 & 12 \\
2001 & 707762.6056 & 707762.61 & 13 \\
1000 & 696042.3955 & 696042.4 & 14 \\
1999 & 690454.1149 & 690454.11 & 15 \\
1995 & 674985.7362 & 674985.74 & 16 \\
1998 & 668733.6989 & 668733.7 & 17 \\
1994 & 643667.4068 & 643667.41 & 18 \\
1993 & 570788.9724 & 570788.97 & 19 \\
\end{tabular}

state launched a government investment program, it does not produce immediate results on infrastructure. So with the private investment affected, comprehensive performance was reduced respectively 1239586.3 and 1244582.3 in 2010 and 2011.

\section{Analysis of Results and Summary}

Using the method of factor analysis to select the driving factors of infrastructure promoting private investment in Nanjing city, the results showed that: the cumulative variance contribution rate of the first principal component reached $84.559 \%$, which also shows a main factor can express sufficient information of the original data. The main ingredient load in the road area per capita, consumption of electricity power, telephone penetration, sewage treatment capacity, capacity utilization of industrial solid waste is relatively large. From the composite score, except in 1996 and 1998, 1999 and 2000 as well as 2001 and 2010, the composite score is increasing year by year, the composite score in 1992 is at the lowest level 468795.87, in 2008 the score is 1308840.4 ranked first, which also shows the role of infrastructure to promote private investment are larger and larger with the continuous improvement of infrastructure. As the transportation is more smoothly, energy efficiency is higher, the communication becomes more convenient, and recycling rate of "three wastes" turns higher, the folk investment level is rising. Therefore, this paper thinks that infrastructure has a promoting effect on the private investment. The level of infrastructure is bottlenecks in economic development, and we should continue to improve its quantity and quality.

\section{References}

[1] Liu, J.S. and Shi, Z.X. (2004) The Crowding out Effect Analysis of Government Expenditure on the Residents' Consumption, Private Investment in China. Jilin University, Changchun.

[2] Yin, W.J. and Wang, L.L. (2010) Study on the Effect of Public Investment in Rural Areas on the Investment of Rural Households. Northwest Agriculture and Technology University, Shanxi.

[3] Shi, S.Q. and Qu, Z. (2010) Study the Impact of Government Investment on Private Investment in the Process of Industrialization in China. Dongbei University of Finance and Economics, Liaoning.

[4] Chen, Z.L. and Wang, L. (2010) Study on the Relationship between Government Investment and Private Investment and Economic Growth. Capital University of Economics and Business, Beijing.

[5] Zheng, Q.F., Wang, D. and Kan, D.X. (2011) Space Measure of the Effect of Extrusion (into) of Government Investment in China. The Journal of Finance Research.

[6] Liao, J.X. (2007) Countermeasure Choices of Promoting Private Investment. Amoy University, Xiamen.

[7] Zhang, W.J. (2008) Urban Infrastructure Investment Efficiency, Economies of Scale Evaluation and Decision Management Research. Tongji University, Shanghai. 
Scientific Research Publishing (SCIRP) is one of the largest Open Access journal publishers. It is currently publishing more than 200 open access, online, peer-reviewed journals covering a wide range of academic disciplines. SCIRP serves the worldwide academic communities and contributes to the progress and application of science with its publication.

Other selected journals from SCIRP are listed as below. Submit your manuscript to us via either submit@scirp.org or Online Submission Portal.
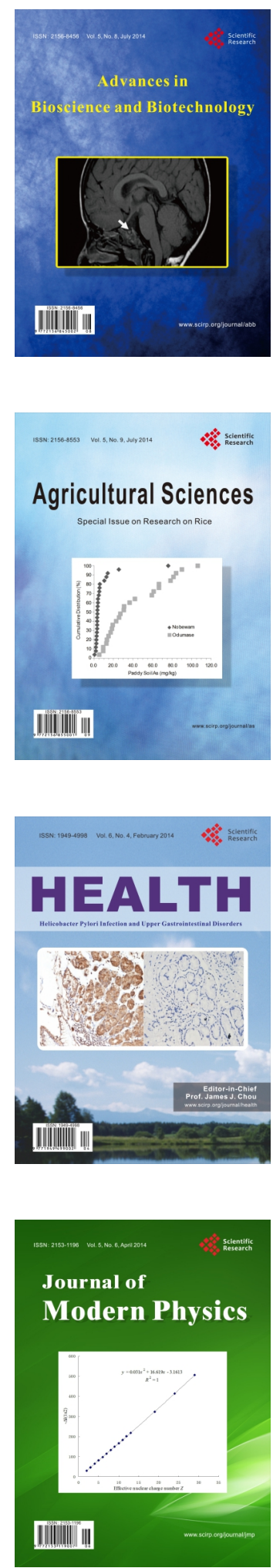
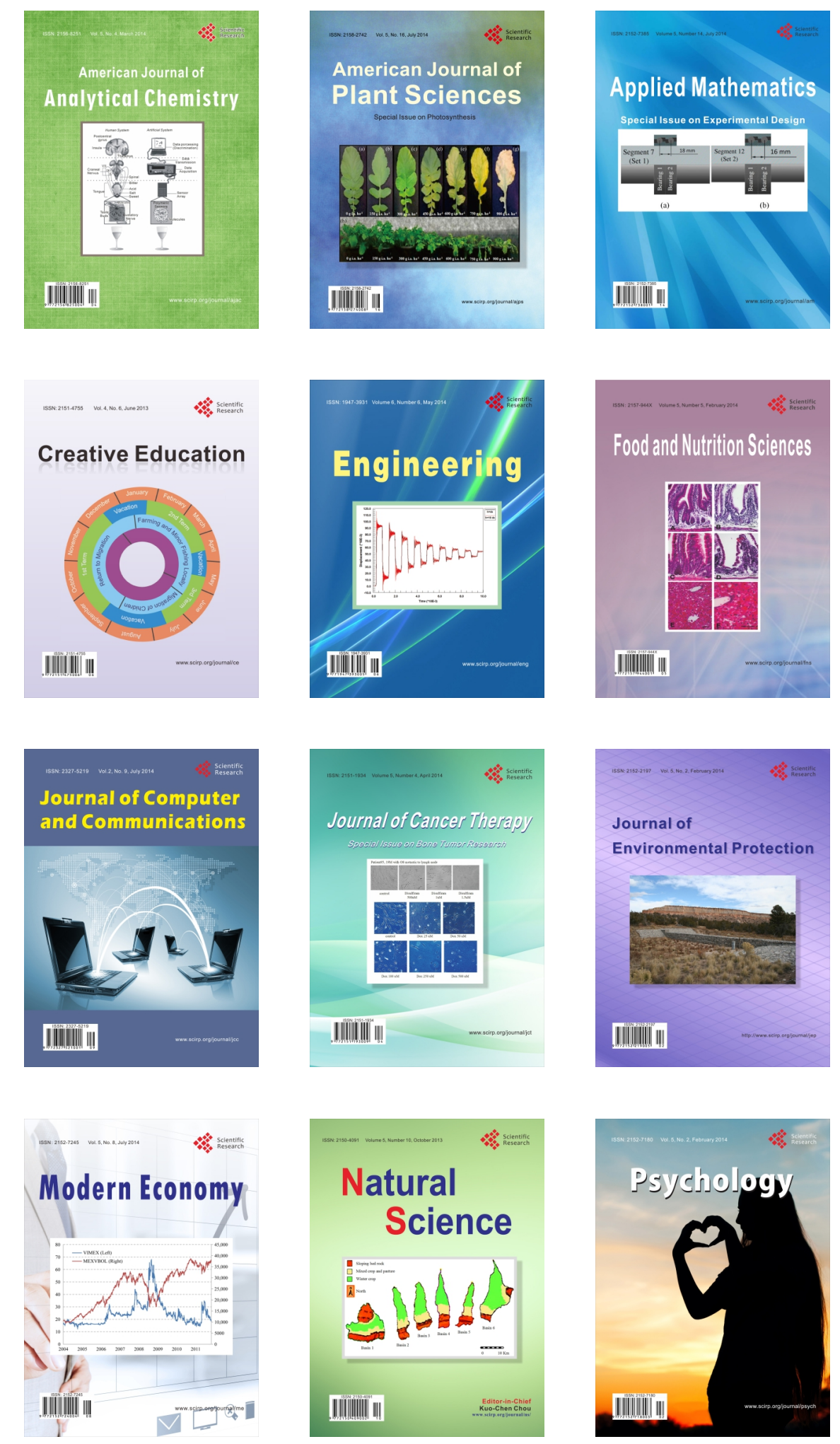